\title{
CALCULATING SEDIMENT COMPACTION FOR RADIOCARBON DATING OF INTERTIDAL SEDIMENTS
}

\author{
M I Bird ${ }^{1,2} \bullet$ L K Fifield ${ }^{3} \cdot$ S Chua $^{1} \bullet$ B Goh $^{1}$ \\ ABSTRACT. This study estimates the maximum and minimum degrees of autocompaction for radiocarbon-dated Holocene \\ mangrove sediments in Singapore, in order to correct apparent sediment accretion rates for the effects of sediment compres- \\ sion due to autocompaction. Relationships developed for a suite of modern (surface) sediment samples between bulk density, \\ particle-size distribution, and organic matter content were used to estimate the initial (uncompacted) bulk density of buried \\ and variably compressed Holocene sediments, based on the grain-size distribution and organic matter content of the sediment. \\ The difference between measured (compacted) and initial (uncompacted) bulk density of each buried sediment interval can \\ be interpreted as the amount of length shortening experienced by each interval since burial. This allows the elevation of sam- \\ ples selected for ${ }^{14} \mathrm{C}$ dating to be corrected for the effects of autocompaction of the underlying sediment sequence, so that \\ accurate estimates of vertical sediment accretion rates can be calculated.
}

The 3 Holocene mangrove sequences analyzed and dated for this study ranged in age from 2000 to 8500 cal BP. The effects of autocompaction are significant, even in comparatively thin sequences, with subsidence of up to $56 \mathrm{~cm}$ calculated for carbon-dated samples presently $2 \mathrm{~m}$ above incompressible basement. The vertical sediment accretion rates for these mangrove sequences ranged from 0.99 to $6.84 \mathrm{~mm} / \mathrm{yr}$ and carbon sequestration rates ranged from 0.9 to $1.7 \mathrm{t} / \mathrm{ha} / \mathrm{yr}$, all within the range observed for comparable Holocene and modern mangrove sediments elsewhere.

\section{INTRODUCTION}

Autocompaction refers to the tendency of newly deposited sediments to increase in bulk density over time through compaction, as new sediments are deposited above them. This leads to the gradual subsidence of Holocene sedimentary sequences "insidiously, continuously and irreversibly lowering the level of the (ground) surface, especially where the sequence beneath is rich in silts and peat..." (Allen 2000).

This compaction and subsidence, in turn, creates space for the continued vertical accretion of new sediment in marginal marine and estuarine environments. Radiocarbon dating of organic and carbonate material from such sediments has been widely used to determine relative sea-level histories through the Holocene (e.g. Pirazzoli 1996) as well as for the calculation of vertical sediment accumulation rates (e.g. Ellison and Stoddart 1991; Ellison 1993) and carbon sequestration rates (e.g. Fujimoto 2000).

While autocompaction does not effect the calculation of mass accumulation rates of mineral or organic matter, it does potentially introduce large errors into the calculation of rates of sea-level rise and vertical sediment accretion rates (Allen 2000; Stanley and Hait 2000). This is because a sample selected for dating from a particular elevation in a sedimentary sequence will have been lowered since deposition by autocompaction of the sediment pile beneath it. The degree to which a sample has been lowered will be a time-dependent function of the thickness and type of sediments beneath it and the thickness and type of sediment subsequently accumulated above it. Sands tend to have a comparatively high initial bulk density and are relatively incompressible, whereas fine-grained sed-

\footnotetext{
${ }^{1}$ National Institute of Education, Nanyang Technological University, 1 Nanyang Walk, Singapore, 637616.

${ }^{2}$ Present address: School of Geography and Geosciences, University of St. Andrews, St. Andrews, Fife, KY16 9AL, Scotland, United Kingdom. Corresponding author. Email: Michael.bird@st-andrews.ac.uk.

${ }^{3}$ Department of Nuclear Physics, Research School of Physical Sciences and Engineering, Australian National University, Canberra, A.C.T. 0200, Australia.
} 
iments (silts and clays) and peaty material have low initial bulk density, but may be compacted by $40-80 \%$ when buried a few tens of meters (Allen 2000).

The rate of autocompaction is likely to be rapid in the initial stages (Cahoon and Lynch 1997), slowing asymptotically to zero as it approaches a maximum value determined again by the characteristics and thickness of sediment pile above (Allen 2000). While, in principle, the effects of autocompaction can be modeled (Allen 2000), in many cases the timing of the imposition of the sediment load above a sample collected for ${ }^{14} \mathrm{C}$ dating will not be known in detail.

Since the time dependence of autocompaction is often unknowable, this study instead calculates the maximum amount of compaction that could have occurred to a given interval of sediment within a sedimentary sequence. This is obtained by comparison of the measured (compacted) dry bulk density of the sample and a calculated initial (uncompacted) dry bulk density of the sample, determined on the basis of the particle size distribution and organic matter content of the compacted sample. The study examines mangrove sediments in Singapore but, in principle, can be applied to any intertidal sediments.

\section{EXPERIMENTAL TECHNIQUES}

\section{Conceptual Framework}

The major determinants of the bulk density of a sediment sample are its particle size distribution, particularly the proportion of fine mineral material, and the proportion of organic material. In this study, fine minerals (silt and clay) are operationally defined as material $<63 \mu \mathrm{m}$ in size. Organic matter content is defined as (i) the total organic carbon content of the sample, and (ii) the mass loss on ignition of material $>63 \mu \mathrm{m}$ in size. The loss on ignition measurements were made on the $>63$ $\mu \mathrm{m}$ fraction as this reduces complications that might arise from the dewatering of clays and amorphous phases; also, it is possible that large fragments of organic detritus exert a greater control on the compressibility of a sediment sample than fine organic matter.

It is assumed that when initially deposited, a sediment sample will have a wet bulk density largely determined by the above parameters. In the intertidal zone, where the sediment surface is exposed and partly drained with each tidal cycle, sediments can undergo initial settling into a coherent mass of sediment with a definable sediment surface. In detail, bulk density may be influenced by elevation in the intertidal zone and, thus, the amount of time over which the sediment pile can drain in a single tidal cycle, but this complication is not addressed in this study.

Carbon in mangrove sediments will continue to be mineralized by microbial processes after burial, but carbon is also added into the sub-surface sediments as dead root biomass. Alongi et al. (2001) found that mineralization efficiencies for mangrove sediments in Thailand ranged from 27 to $40 \%$ in the mixed layer $(16-38 \mathrm{~cm})$. The same study also found that carbon densities through the mixed layer could both increase and decrease with depth, depending on location and season, suggesting that there is no reason to expect that sediment buried below the mixed layer will have a systematically lower carbon content than sediment at the surface. Once sediment is buried below the mixed layer, mineralization may proceed, but the rates of mineralization can be considered small for the purposes of this study (Alongi et al. 2000).

It is therefore assumed that once buried, a given volume of sediment will retain its particle size distribution and organic matter content. Thus, the amount of compaction of a sediment interval can be estimated from the difference between the bulk density of the compacted sediment and the bulk density of a modern (uncompacted) sediment sample with the same grain size and organic matter char- 
acteristics. The estimate of initial bulk density for a compacted sample is derived from empirical relationships between dry bulk density, particle size distribution, and organic matter content developed for a suite of modern intertidal sediment samples of widely divergent characteristics from mangrove regions in Singapore (as described below).

This comparison can be repeated for successive intervals up a sedimentary sequence, and the cumulative amount of compaction can be calculated from the base of a sedimentary sequence to the elevation from which a sample was taken for ${ }^{14} \mathrm{C}$ dating. Since some, or all, of this compaction could have occurred before the sample was deposited, however, this amount of compaction does not necessarily reflect the amount of lowering that the sample has experienced since deposition. Because the time dependence of the rate of autocompaction is in general not known, only the 2 end-member values for the cumulative lowering of a sample from its original depositional elevation are well defined.

The first end-member assumes that autocompaction occurs rapidly after deposition of the sediment. In this case, the amount of lowering of a sample selected for ${ }^{14} \mathrm{C}$ dating at any point in the sedimentary sequence is zero, because the sedimentary pile beneath was already fully compacted before the sample selected for dating was deposited. The second end-member assumes that compaction of the sequence underlying a sample collected for dating occurs only after deposition of the sample. This yields the maximum amount of lowering that a sample could possibly have experienced. Neither of these end-members is realistic, but the "true" amount of lowering experienced by a sample must lie between these 2 values and can be reported as the average of the two, plus or minus half the difference between the two.

\section{Samples and Analysis}

\section{Modern Samples}

A set of 45 modern reference sediment samples $(0-5 \mathrm{~cm})$ and 12 sub-recent sediments $(15-20 \mathrm{~cm})$ were collected from mangrove environments distributed around the coast of Singapore, with sample locations selected in order to obtain as wide a range of particle size distributions and carbon contents as possible. In each case, a PVC tube $3.8 \mathrm{~cm}$ in diameter was pushed into the sediment surface to a depth of $5 \mathrm{~cm}$ from the sediment surface $(0-5 \mathrm{~cm})$ or from a pit dug to $15 \mathrm{~cm}$ depth $(15-20 \mathrm{~cm})$. Then, each sediment was quantitatively extracted, yielding a volume of $175 \mathrm{~cm}^{3}$ of wet sediment. This sediment was transferred to a plastic bag and sealed for transport to the laboratory where the wet weight of sediment was determined. While sampling does compact the sediment in the tube, the weight of sediment collected is representative of the uncompacted material in the volume sampled, and, hence, compaction during sampling does not affect the bulk density calculations.

Approximately $20-30 \mathrm{~g}$ of wet sediment was weighed and then dried for 2 days at $60^{\circ} \mathrm{C}$ to determine water content and dry bulk density of each sample (grams of dry sediment per cubic $\mathrm{cm}$ of original volume). A separate aliquot of $30 \mathrm{~g}$ of wet sediment was weighed and then wet sieved at $63 \mu \mathrm{m}$ to separate the most compressible silt and clay fraction of the sediment. The $>63-\mu \mathrm{m}$ fraction was dried and weighed, and the proportion of $<63-\mu \mathrm{m}$ material calculated by difference after correcting for water content. The dried $>63-\mu \mathrm{m}$ fraction was then sieved at $2000 \mu \mathrm{m}$ and $500 \mu \mathrm{m}$ and these fractions weighed to obtain more detailed information on particle size distribution. All $>63-\mu \mathrm{m}$ material was then recombined into a single sample for the determination of loss on ignition in the $>63-\mu \mathrm{m}$ fraction $\left(\mathrm{LOI}_{>63 \mu \mathrm{m}}\right)$. This was calculated from the weight loss accompanying the heating of $1-2 \mathrm{~g}$ of wellmixed $>63-\mu \mathrm{m}$ material in a furnace at $450{ }^{\circ} \mathrm{C}$ for $4 \mathrm{hr}$. 
Total organic carbon and total inorganic carbon were determined on dried and crushed aliquots of bulk sediment ( $\sim 150 \mathrm{mg})$ using a Shimadzu total carbon analyzer. Total carbon (TC) was determined by combustion at $900{ }^{\circ} \mathrm{C}$, total inorganic carbon (TIC) by acidification, and total organic carbon (TOC) from the difference between the TC and TIC determinations.

Relationships between calculated dry bulk density (DBD), fraction of $<63-\mu \mathrm{m}\left(\mathrm{F}_{<63 \mu \mathrm{m}}\right)$ material and either TOC or $\mathrm{LOI}_{>63 \mu \mathrm{m}}$ for all modern samples were explored using Tablecurve-3D surface fitting software.

\section{Compacted Samples}

Three sedimentary sequences buried to different depths were used to test the "decompaction" methodology (Figure 1). The first was a $\sim 2.5-\mathrm{m}$ sequence of mangrove peat underlying modern mangroves at Lim Chu Kang in northwest Singapore (LCK-4; $1.446737^{\circ} \mathrm{N}, 103.709312^{\circ} \mathrm{E}$; determined by differential GPS to $\pm 0.5 \mathrm{~m}$ ). The core was obtained using a 50 -mm-diameter modified Livingstone piston corer. The base of the sequence $(-2.0 \mathrm{~m}$ rsl: relative to mean sea-level) represents a pre-Holocene-transgression weathered profile developed on highly compacted but not lithified Pleistocene "Old Alluvium." The profile grades upwards from peaty muds and sands to essentially pure peat $+0.5 \mathrm{~m}$ above modern mean sea level. The sediments were extracted in $1-\mathrm{m}$ increments, with each section extruded on site and wrapped in plastic to prevent water loss. In the laboratory, each section of the core was cut into $10-\mathrm{cm}$ segments and weighed. Thereafter, sample preparation and analysis protocols followed those described above for the modern sediments.

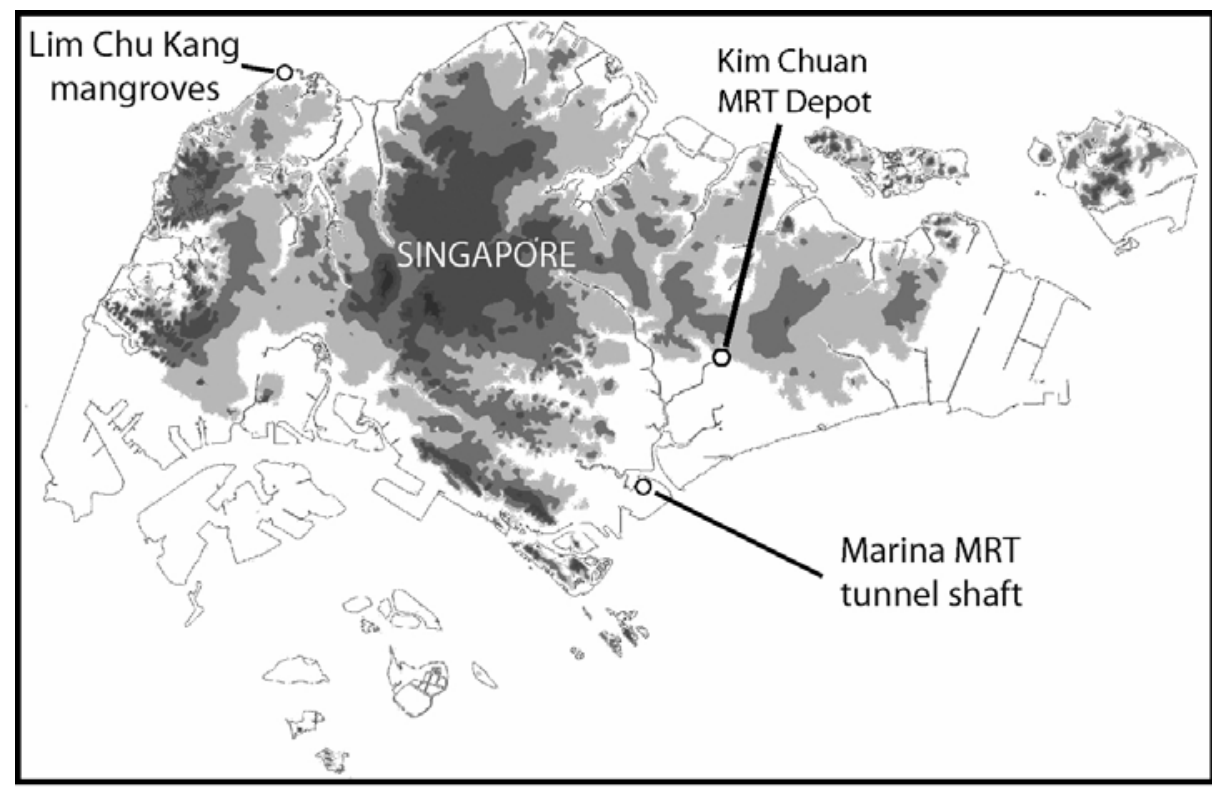

Figure 1 Locations of the Holocene mangrove sequences analyzed in this study. The outline of modern Singapore is shown as a line. The extent of Singapore above tidal influence during the mid-Holocene sea-level highstand is shown as a shaded area. Higher land is shown with darker shading.

The second sequence was exposed in a deep excavation in the downtown area for the future underground Marina Mass Rail Transit line (MAR-5; $1.290896^{\circ} \mathrm{N} ; 103.861090^{\circ} \mathrm{E}$ ). A $1.5-\mathrm{m}$ sequence from -7.82 to $-6.32 \mathrm{~m}$ rsl was sampled from a vertical face by pushing a sample tube horizontally 
into the exposure at $10-\mathrm{cm}$ intervals. The base of the sequence $(-7.82$ to $-7.42 \mathrm{~m})$ represents a preHolocene-transgression soil developed on the sedimentary "Old Alluvium," overlain from -7.42 to $-7.0 \mathrm{~m}$ by a sandy mangrove peat, overlain in turn by $\sim 4 \mathrm{~m}$ of shallow marine clays. This location was originally beneath the sea, but reclamation in the 1970 s added another $\sim 5 \mathrm{~m}$ of sand to the top of the sedimentary pile, raising the sediment surface about $4 \mathrm{~m}$ above mean sea level. All samples collected from this sequence were treated in the manner described for the modern sediment samples.

The third sequence was sampled from the excavation that will become the Kim Chuan underground train servicing facility for the Circle Line Mass Rapid Transit train line (KCD-6; $1.340096^{\circ} \mathrm{N}$ $\left.103.886743^{\circ} \mathrm{E}\right)$ The samples were collected from an excavation face exposed from +1.0 to $+3.0 \mathrm{~m}$ rsl. The lowermost $30 \mathrm{~cm}$ of the section represents highly compacted "Old Alluvium" transgressed between +1.3 and $+1.6 \mathrm{~m}$ rsl by Holocene interbeds of clay and sandy clay. A sequence of mangrove mud was deposited from $+1.6 \mathrm{~m}$, grading gradually into a mangrove peat at $+2.6 \mathrm{~m}$. The top of the natural sequence was at $+3.0 \mathrm{~m}$, but this was overlain by $1-2 \mathrm{~m}$ of fill material (probably dumped in the 1950s) that was not sampled. All samples were collected as described for MAR-5, and were subsequently treated in the manner described for the modern sediment samples.

For all sedimentary sequences, woody material was selected from the basal Holocene layers and from the upper parts of the sequences for ${ }^{14} \mathrm{C}$ dating. Samples were given an acid-base-acid pretreatment before analysis by accelerator mass spectrometry at the Research School of Physical Sciences and Engineering, Australian National University (ANU-A prefix) or by conventional scintillation counting at the Research School of Earth Sciences, Australian National University (ANU-prefix).

\section{RESULTS}

\section{Modern Samples}

The modern samples covered a wide spectrum of compositions from peaty sands and muds to inorganic sands. DBD for the samples ranged from $0.12 \mathrm{~g} / \mathrm{cm}^{3}$ to $1.62 \mathrm{~g} / \mathrm{cm}^{3}$, water content from $19.4 \%$ to $83.3 \%, \mathrm{~F}_{<63 \mu \mathrm{m}}$ from $0.44 \%$ to $85.5 \%$, TOC from $0.41 \%$ to $34.7 \%$, and $\mathrm{LOI}_{>63 \mu \mathrm{m}}$ from $0.56 \%$ to $85.6 \%$. In general, coarse-grained sediments were characterized by high DBD and low water content, TOC, $\mathrm{F}_{<63 \mu \mathrm{m}}$ and $\mathrm{LOI}_{>63 \mu \mathrm{m}}$, while fine-grained sediments were characterized by low DBD and high water content, $\mathrm{F}_{<63 \mu \mathrm{m}}$ and $\mathrm{LOI}_{>63 \mu \mathrm{m}}$, and variable TOC. There are good relationships between DBD and water content, TOC, and $\mathrm{LOI}_{>63 \mu \mathrm{m}}$, but poor correlation between DBD and $\mathrm{F}_{<63 \mu \mathrm{m}}$, suggesting that organic content is a more significant determinant of DBD than particle size distribution (Figure 2). Samples from $15-20 \mathrm{~cm}$ tend to plot above the line defined by the 0-5-cm samples, suggesting that these samples have been compacted to a variable degree.

\section{Compacted Samples}

Core LCK-4 (Figure 3) is generally composed of muddy to sandy peats with less than $10 \%$ of $>2000-\mu \mathrm{m}$ material and $20-50 \%$ of $<63-\mu \mathrm{m}$ material, except for a sandier unit from -0.4 to -0.1 $\mathrm{m}$ rsl. Water content and DBD tend to decrease up the core, while TOC increases up the core from $\sim 2$ to $10 \%$. $\mathrm{LOI}_{>63 \mu \mathrm{m}}$ remained approximately constant at around $10 \%$ up to $+0.1 \mathrm{~m}$ rsl, increasing in the uppermost part of the core to $40-50 \%$. This core spanned a range of sediment types, and, hence, some uncertainty is introduced by the compacting effect of the coring process. The degree of compaction along the length of the core may not be uniform and may vary depending on the compressibility of the sediments encountered. This effect is probably small, and is accounted for in the decompaction procedure. 

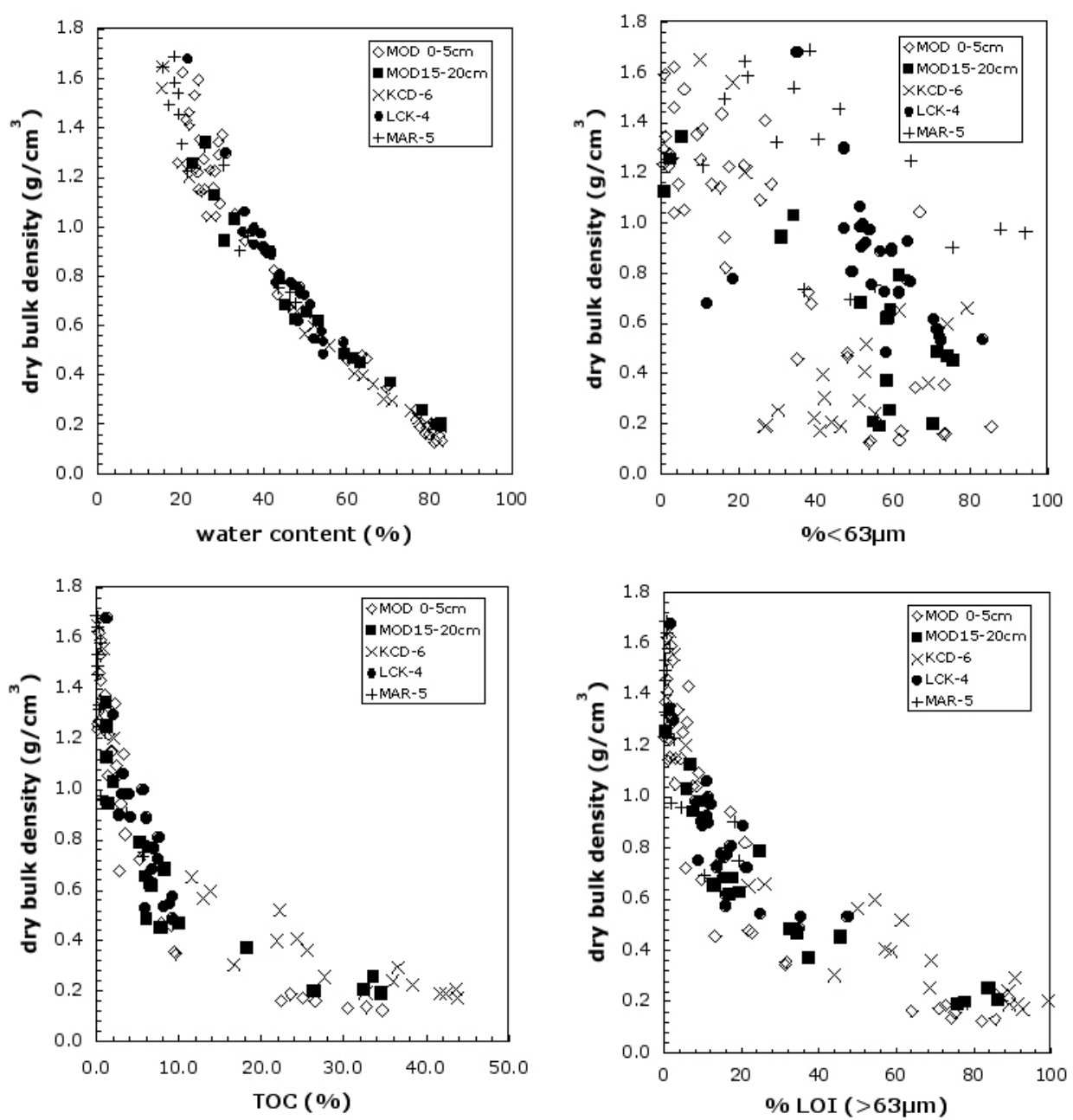

Figure 2 Relationships between $\mathrm{DBD}, \mathrm{F}_{<63 \mu \mathrm{m}}, \mathrm{TOC}$, and $\mathrm{LOI}_{>63 \mu \mathrm{m}}$ for all samples analyzed in this study

The composition of the Holocene sequence of mangrove peat and shelly marine clay in core MAR5 is markedly different from the underlying soil profile (Figure 4). The grain size distribution of the underlying soil was dominated by fractions $>63 \mu \mathrm{m}$, with $\mathrm{F}_{<63 \mu \mathrm{m}}$ being $<50 \%$ in all cases. In the underlying soil, DBD was uniformly very high $\left(>1.5 \mathrm{~g} / \mathrm{cm}^{3}\right)$, water contents were $<20 \%$, and organic matter was present only in very small amounts. In contrast, the mangrove peat was generally composed of sediments containing $>50 \% \mathrm{~F}_{<63 \mu \mathrm{m}}$ material with DBD ranging from 0.6 to $1.0 \mathrm{~g} / \mathrm{cm}^{3}$ and high organic matter content (10-20\% $\mathrm{LOI}_{>63 \mu \mathrm{m}}$ and $\left.2-8 \% \mathrm{TOC}\right)$. The shelly marine clay overlying the peat was dominated by $\mathrm{F}_{<63 \mu \mathrm{m}}$, increasing rapidly towards the top of the section to values in excess of $90 \%$. DBD ranged from $\sim 1.0$ to $1.5 \mathrm{~g} / \mathrm{cm}^{3}$ and both TOC and $\mathrm{LOI}_{>63 \mu \mathrm{m}}$ comprised $<1 \%$ of the material.

As with MAR-5, the soil underlying the Holocene sequence in KCD-6 is characterized by high DBD and, in this case, is dominated by sand-sized material with low TOC (Figure 5). The overlying interbedded sandy muds contain comparatively little organic carbon and high $\mathrm{F}_{<63 \mu \mathrm{m}},(>50 \%)$, with DBD values of $\sim 0.6 \mathrm{~g} / \mathrm{cm}^{3}$. Above this unit, TOC and $\mathrm{LOI}_{>63 \mu \mathrm{m}}$ increase to about $+2.0 \mathrm{~m}$ and then remain 


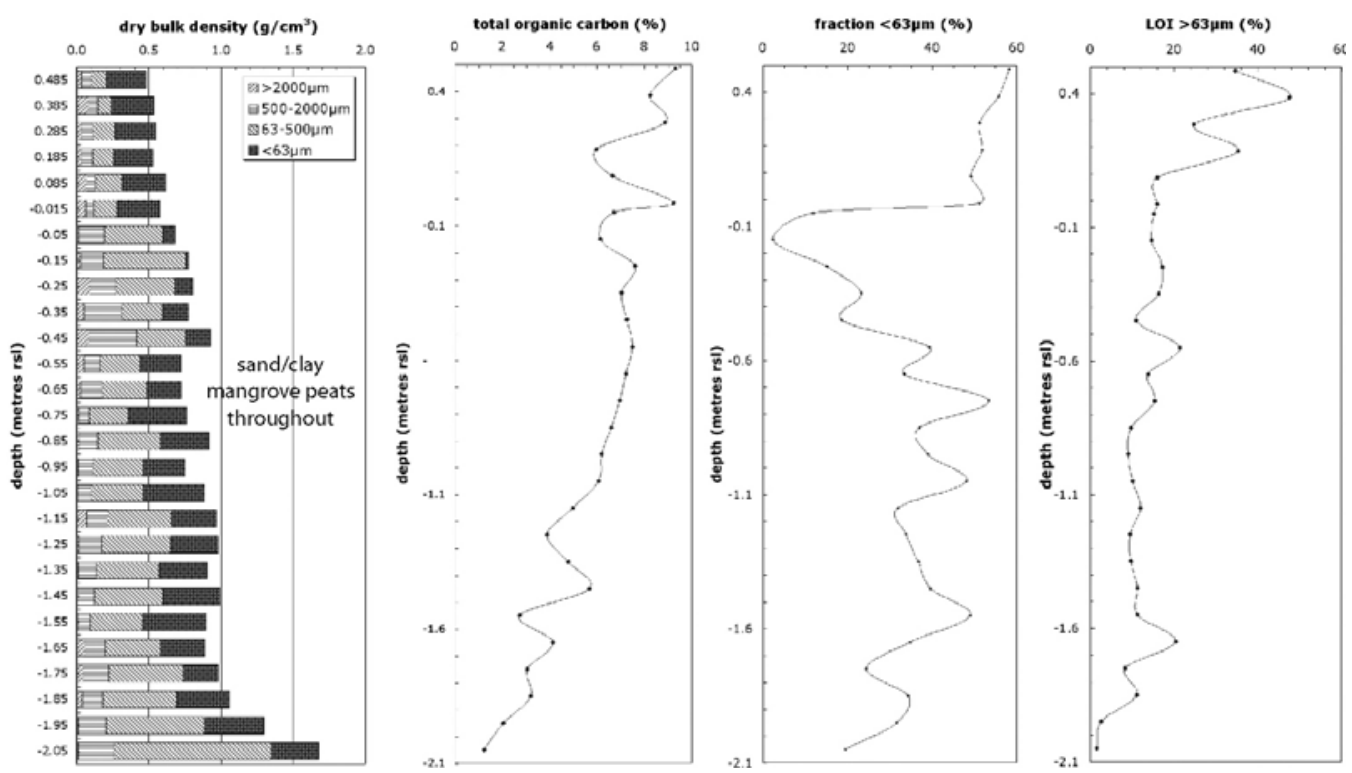

Figure 3 Contributions of different size fractions to the observed bulk density of LCK-4. Also shown are variations in $\mathrm{F}_{<63 \mu \mathrm{m}}, \mathrm{TOC}$, and $\mathrm{LOI}_{>63 \mu \mathrm{m}}$ through the sequence.
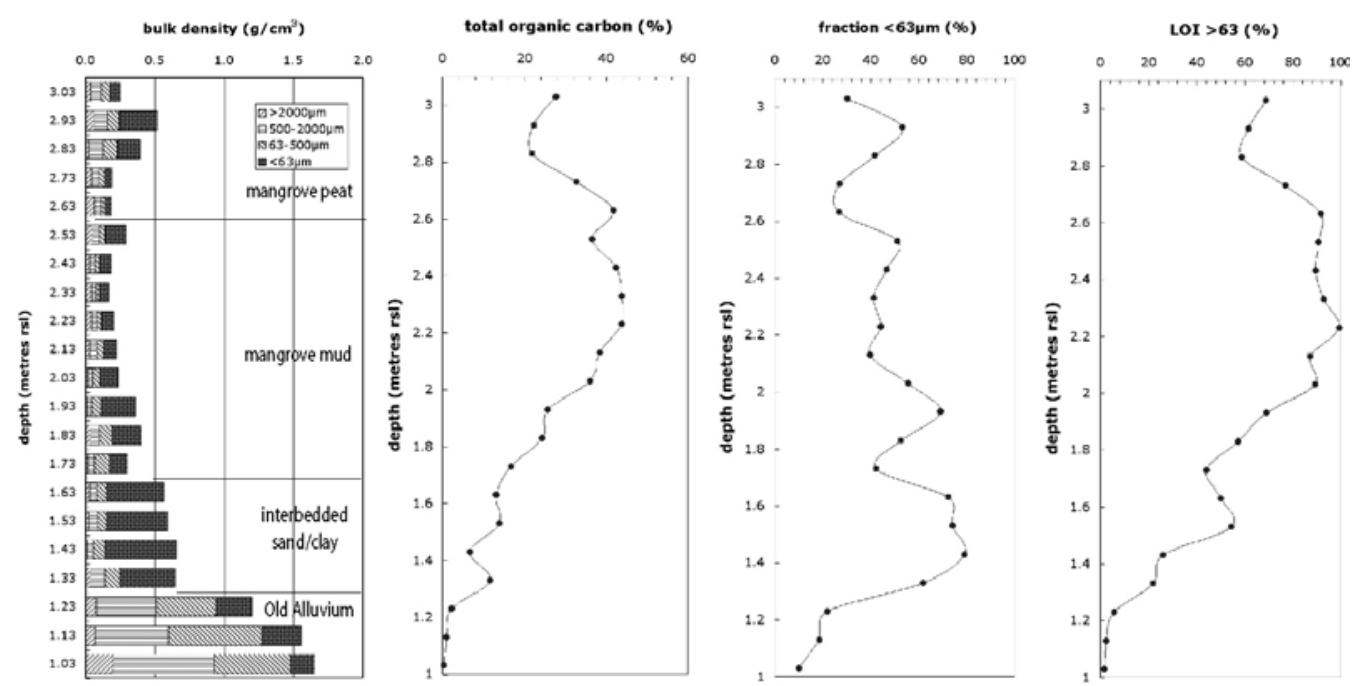

Figure 4 Contributions of different size fractions to the observed bulk density of MAR-5. Also shown are variations in $\mathrm{F}_{<63 \mu \mathrm{m}}, \mathrm{TOC}$, and $\mathrm{LOI}_{>63 \mu \mathrm{m}}$ through the sequence.

approximately constant at $30-40 \%$ and $80-90 \%$, respectively, decreasing slightly in the uppermost $30 \mathrm{~cm}$ of the section. DBD values are $<0.4 \mathrm{~g} / \mathrm{cm}^{3}$ throughout this interval except in the upper $30 \mathrm{~cm}$, reflecting the very organic-rich nature of the sediments.

The ${ }^{14} \mathrm{C}$ dates obtained from all 3 sediment sequences are shown in Table 1, and range from 1880 to $7650 \mathrm{BP}$, indicating that these sequences were deposited through the Holocene, following sea-level rise after the Last Glacial Maximum (Hesp et al. 1998). 

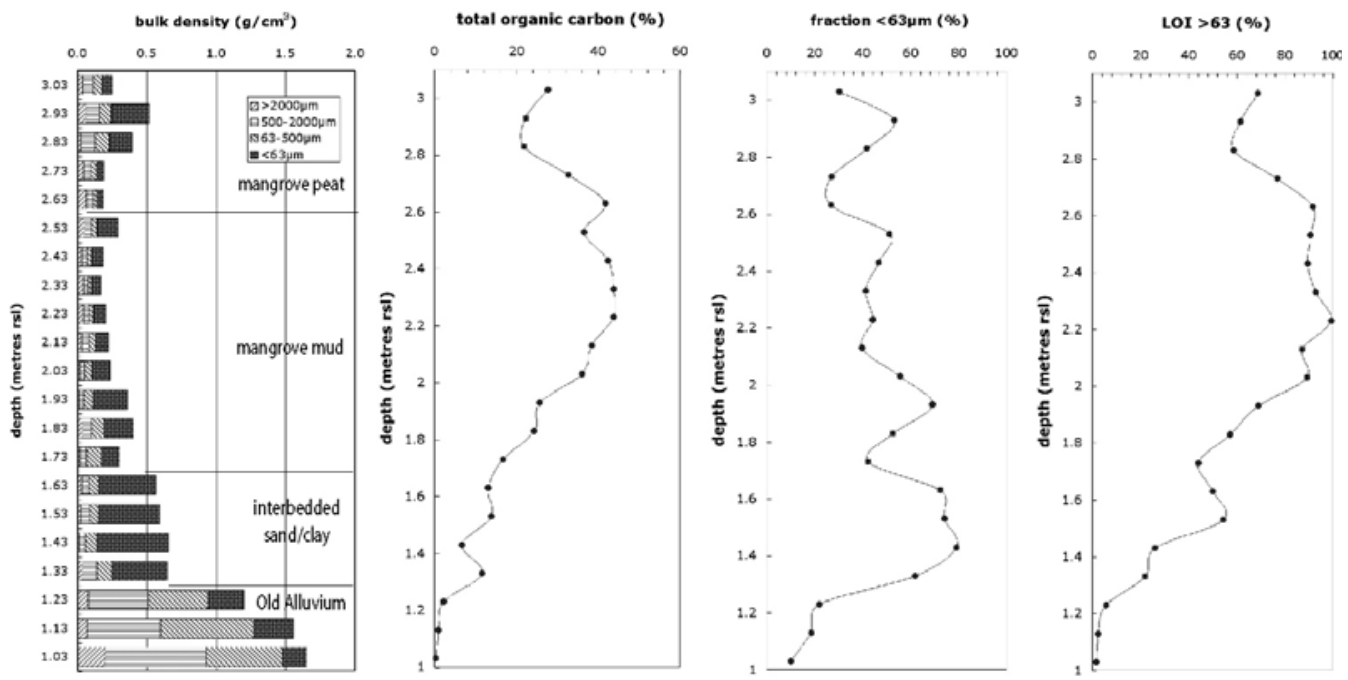

Figure 5 Contributions of different size fractions to the observed bulk density of LCK-6. Also shown are variations in $\mathrm{F}_{<63 \mu \mathrm{m}}, \mathrm{TOC}$, and $\mathrm{LOI}_{>63 \mu \mathrm{m}}$ through the sequence.

Table $1{ }^{14} \mathrm{C}$ dates for sedimentary sequences analyzed in this study. All samples were woody material and have been corrected for fractionation using an assumed $\delta^{13} \mathrm{C}$ value of $-25 \%$. Calibration from ${ }^{14} \mathrm{C}$ yr (yr BP) to calendar yr (cal BP) was achieved using the Calib 4.4 dataset (Stuiver et al. 1998). Only the calibrated date with the highest probability is shown.

\begin{tabular}{llll}
\hline & $\mathrm{m}(\mathrm{rsl})$ & $\mathrm{yr}$ BP & cal BP \\
\hline KCD-6 & & & \\
ANU-11808 & +2.63 & $4470 \pm 120$ & $5300-4970$ \\
ANU-11807 & +1.63 & $5270 \pm 170$ & $6210-5890$ \\
ANU-11806 & +1.33 & $6300 \pm 80$ & $7315-7160$ \\
& & & \\
LCK-4 & & & \\
ANUA-22221 & -0.01 & $2400 \pm 190$ & $2740-2310$ \\
ANUA-25705 & -0.35 & $1880 \pm 190$ & $2000-1570$ \\
ANUA-22223 & -2.04 & $7090 \pm 190$ & $8040-7715$ \\
& & & \\
MAR-5 & & & \\
ANU-11841 & -6.97 & $7530 \pm 80$ & $8390-8315$ \\
ANU-11840 & -7.42 & $7650 \pm 100$ & $8540-8360$ \\
\hline
\end{tabular}

\section{DISCUSSION}

Figure 6 shows the relationship between DBD, $\mathrm{F}_{<63 \mu \mathrm{m}}$, and TOC for modern sediments $(0-5 \mathrm{~cm})$, while Figure 7 shows the relationship between DBD, $\mathrm{F}_{<63 \mu \mathrm{m}}$, and $\mathrm{LOI}_{>63 \mu \mathrm{m}}$ for modern sediment. These figures show that the DBD of the modern intertidal sediments can be predicted by a knowledge of $\mathrm{F}_{<63 \mu \mathrm{m}}$ and either TOC or $\mathrm{LOI}_{>63 \mu \mathrm{m}}$ using the following equations:

$$
\begin{gathered}
\ln (\mathrm{DBD})=0.316+\left\{\left[\left(0.0032 *\left(\mathrm{~F}_{<63 \mu \mathrm{m}}\right)\right] \times \ln \left(\mathrm{F}_{<63 \mu \mathrm{m}}\right)\right\}+\left\{\left[(0.0665 \times(\mathrm{TOC})]^{0.5} \times \ln (\mathrm{TOC})\right\} \mathrm{r}^{2}=0.94\right.\right. \\
\ln (\mathrm{DBD})=0.399+\left[0.0145 \times\left(\mathrm{F}_{<63 \mu \mathrm{m}}\right)\right]+\left[0.0142 \times\left(\mathrm{LOI}_{>63 \mu \mathrm{m}}\right)\right] \mathrm{r}^{2}=0.91
\end{gathered}
$$




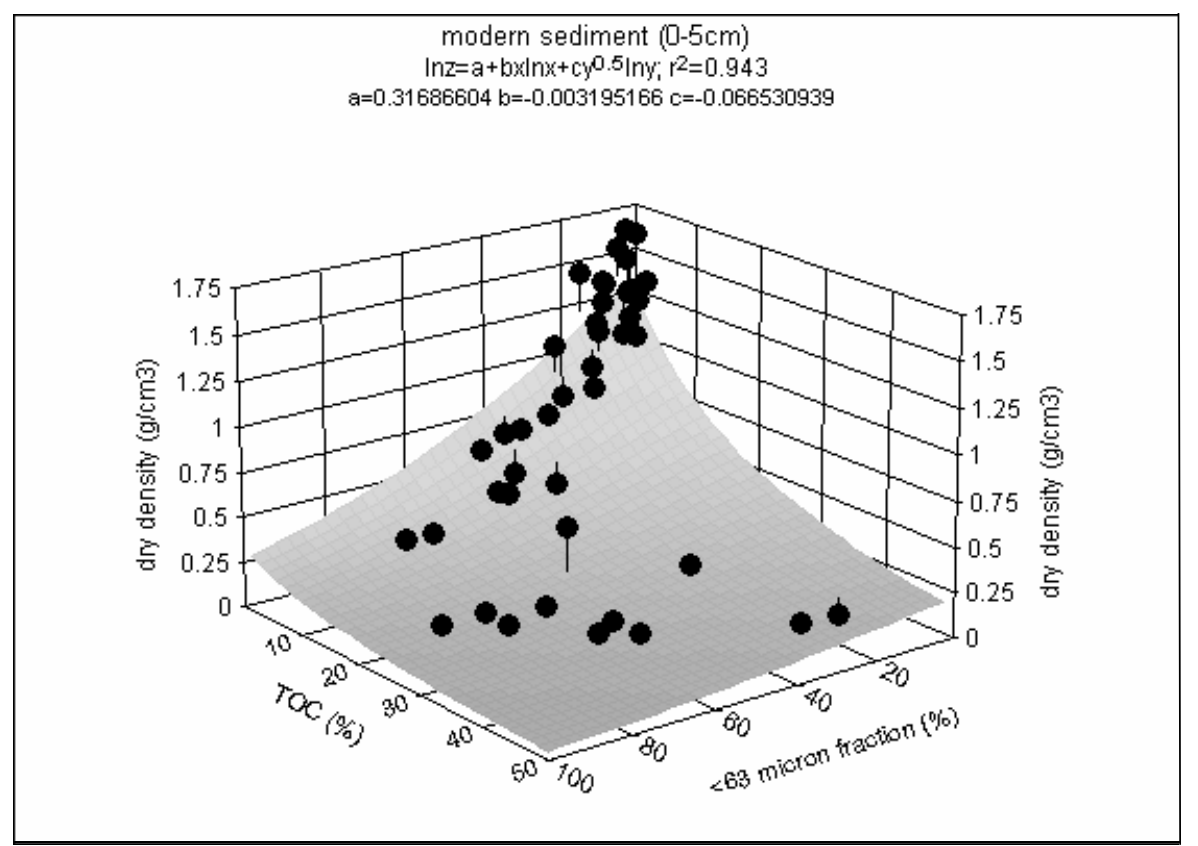

Figure 6 Relationship between DBD, $\mathrm{F}_{<63 \mu \mathrm{m}}$, and TOC for modern $(0-5 \mathrm{~cm})$ mangrove sediments in Singapore

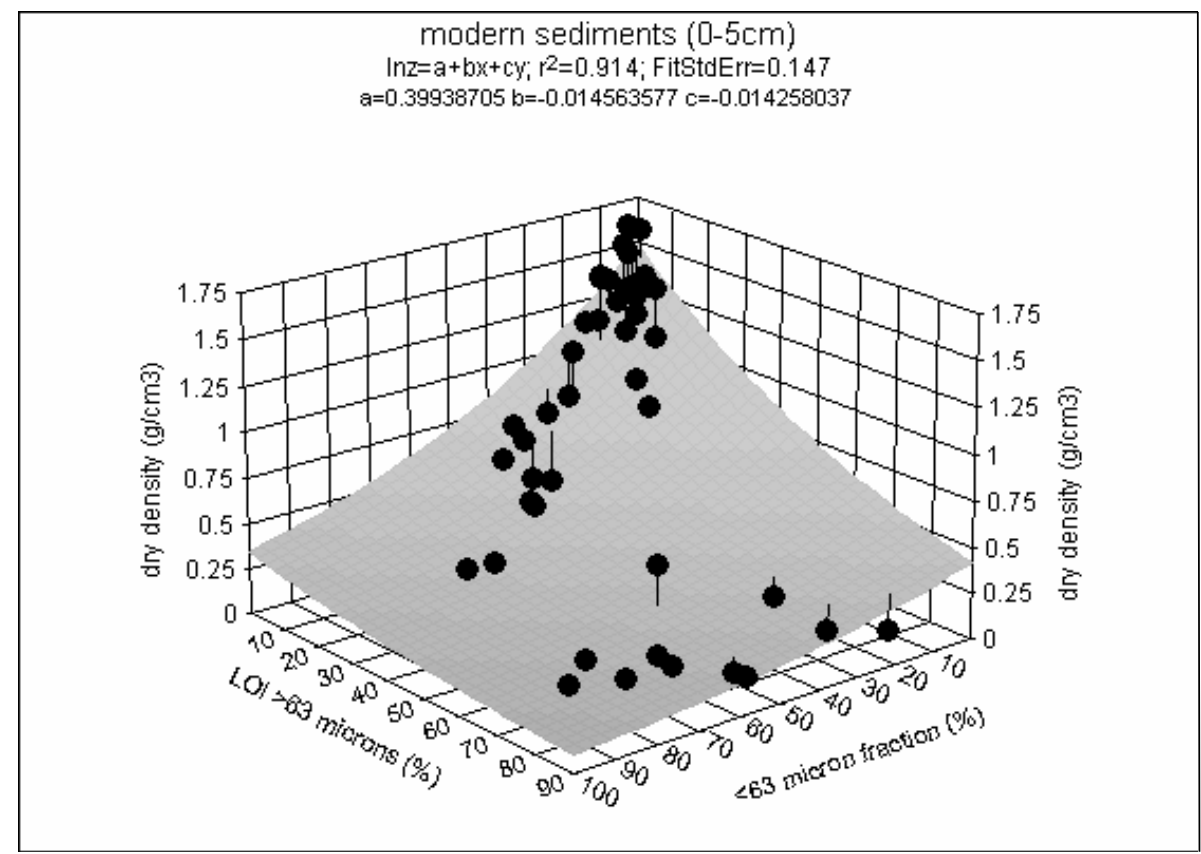

Figure 7 Relationship between $\mathrm{DBD}, \mathrm{F}_{<63 \mu \mathrm{m}}$, and $\mathrm{LOI}_{>63 \mu \mathrm{m}}$ for modern $(0-5 \mathrm{~cm})$ mangrove sediments in Singapore

The fit of both these equations is good, suggesting that the initial "uncompacted" dry bulk density $\left(\mathrm{DBD}_{\mathrm{i}}\right)$ of any sediment interval in a sedimentary sequence can be calculated from a knowledge of the other parameters, all of which can be measured directly. The 2 equations above provide 2 quasiindependent estimates of $\mathrm{DBD}_{\mathrm{i}}$, and, therefore, the average value is used in subsequent calculations. 
From comparison of average calculated $\mathrm{DBD}_{\mathrm{i}}$ with the measured dry bulk density of the sample $\left(\mathrm{DBD}_{\mathrm{f}}\right)$, the initial vertical length $\left(\mathrm{L}_{\mathrm{i}}\right)$ of uncompacted sediment of $\mathrm{DBD}_{\mathrm{i}}$ required to yield a $1-\mathrm{cm}$ vertical interval of compacted sediment of $\mathrm{DBD}_{\mathrm{f}}$ can be calculated via the following equation:

$$
\mathrm{L}_{\mathrm{i}}=1+\left[\left(\mathrm{DBD}_{\mathrm{f}}-\mathrm{DBD}_{\mathrm{i}}\right) / \mathrm{DBD}_{\mathrm{f}}\right]
$$

Application of this relation to 10 -cm intervals along the sedimentary sequence allows determination of the cumulative compaction below any point in the sequence, and, hence, of the maximum amount of lowering that could have been experienced by a sample in the sequence due to compaction of the sediments below it. Due to uncertainties in the sampling and analysis, this equation can yield values less than 1 (apparent expansion). Since expansion under an imposed sediment load is unlikely and an estimate of maximum compaction is required, negative values for the apparent change in length are set to zero.

The percent compaction of each 10 -cm interval in the 3 sampled sedimentary sequences is shown in Figures 8, 9, and 10. Also shown are the calibrated ${ }^{14} \mathrm{C}$ ages for each core and the calculated maximum amount of lowering that could have been experienced by each ${ }^{14} \mathrm{C}$-dated sample. TOC and DBD measurements for these cores allow the calculation of carbon sequestration rates, while the "decompaction" of the cores allows the calculation of maximum rates of sediment accumulation.

Table 2 shows that the average amount of maximum compaction experienced by the sedimentary sequences analyzed in this study ranges from 17 to $55 \%$. While the "true" rate of sediment accretion can only be said to lie between the observed and "decompacted" values, the results do suggest that autocompaction is likely to have a significant impact on sediment accretion rate calculations, even over comparatively narrow intervals, in sediments buried to even shallow depths.

Table 2 Accretion rates calculated assuming rapid compaction (uncorrected accretion rate) and slow compaction (decompacted accretion rate) as described in the text. The probable accretion rate can be reported as the average of these 2 values \pm half the difference between them. Also shown is the average maximum compaction for the intervals over which the accretion rates were calculated, and the depths over which these were calculated are given in Figures 8-10. The carbon sequestration rate was calculated from TOC and $\mathrm{DBD}_{\mathrm{f}}$ values.

\begin{tabular}{lllll}
\hline & $\begin{array}{l}\text { Uncorrected } \\
\text { accretion rate } \\
(\mathrm{mm} / \mathrm{yr})\end{array}$ & $\begin{array}{l}\text { Decompacted } \\
\text { accretion rate } \\
(\mathrm{mm} / \mathrm{yr})\end{array}$ & $\begin{array}{l}\text { Maximum } \\
\text { compaction } \\
(\%)\end{array}$ & $\begin{array}{l}\text { TOC } \\
\text { accumulation } \\
(\mathrm{t} / \mathrm{ha} / \mathrm{yr})\end{array}$ \\
\hline Core/sediment type & $(0.31)$ & $(0.38)$ & 18 & $(0.16)$ \\
LCK-4, mangrove mud/peat & 4.73 & 6.84 & 31 & 1.7 \\
KCD-6, mangrove peat & 0.99 & 1.19 & 17 & 0.91 \\
KCD-6, interbedded sand/clay & 0.25 & 0.56 & 55 & 0.23 \\
\hline
\end{tabular}

The uppermost sample ${ }^{14} \mathrm{C}$ dated in the mangrove unit in MAR-5 may have been lowered by up to $28 \mathrm{~cm}$ by compaction of the underlying $40 \mathrm{~cm}$ of mangrove peat (Figure 8 ). These sediments exhibit the most rapid accretion rate $(4.73-6.84 \mathrm{~mm} / \mathrm{yr})$. Nevertheless, this rate is less than half the rate of sea-level rise between 8350 and 8450 cal BP (Hesp et al. 1998); hence, it is not surprising that the mangrove sequence was rapidly transgressed and buried by marine clay. The calculated maximum compactions for each interval are comparatively high (5-56\%; Figure 8), consistent with the comparatively thick sequence $(9 \mathrm{~m})$ of marine clay and landfill material that overlie the sediments. Given that the mangrove peat is narrow and was deposited over a short time interval, it is likely that the "true" amount of compaction approaches the calculated maximum amount of compaction in this 


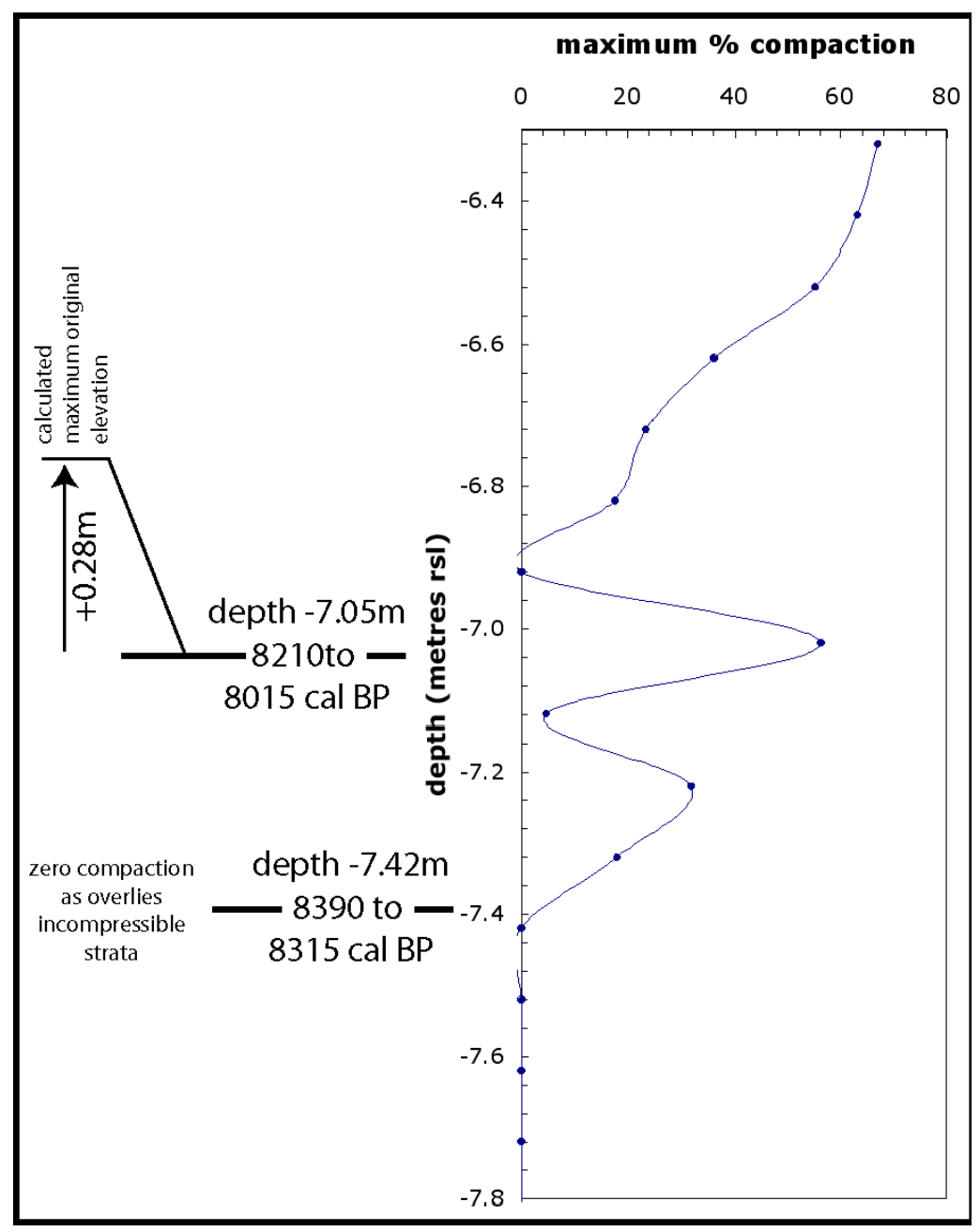

Figure 8 Percent compaction calculated for each 10-cm interval of MAR-5. Also shown is the effect of "decompacting" the sediments on the elevation of samples selected for ${ }^{14} \mathrm{C}$ dating. The lowermost sample is immediately above incompressible basement, and, hence, cannot be lowered by compaction. The approach used in this study yields an estimate of maximum compaction. Since the true amount of compaction is not known, the average of the values for "no compaction" and "maximum compaction" should be used for calculation of accretion rate, with the error given by half the difference between the 2 estimates.

case. Compaction of the interval of marine clay above the mangrove unit has also been significant, increasing from 0 to $67 \%$ as $\mathrm{F}_{<63 \mu \mathrm{m}}$ increases from $11 \%$ to $94 \%$ of the total sediment. Carbon sequestration rates over the period during which the mangrove sequence was deposited averaged $1.7 \mathrm{t} / \mathrm{ha} / \mathrm{yr}$.

Accretion rates for 2 intervals can be calculated for KCD-6. The lowest transgressive unit, an interbedded unit of sand and clay, accumulated in the uppermost intertidal zone beyond the landward fringe of the mangroves at a comparatively low rate of $0.25-0.56 \mathrm{~mm} / \mathrm{yr}$. This sequence exhibits the highest amount of compaction, with the carbon-dated sample at the top of the unit having been lowered by up to $36 \mathrm{~cm}$ by compaction of the underlying $30 \mathrm{~cm}$ of sediment (Figure 9). Carbon sequestration during this interval between $\sim 6000$ and $\sim 7200$ cal BP was low $(0.23 \mathrm{t} / \mathrm{ha} / \mathrm{yr})$, consistent with its depositional context. 


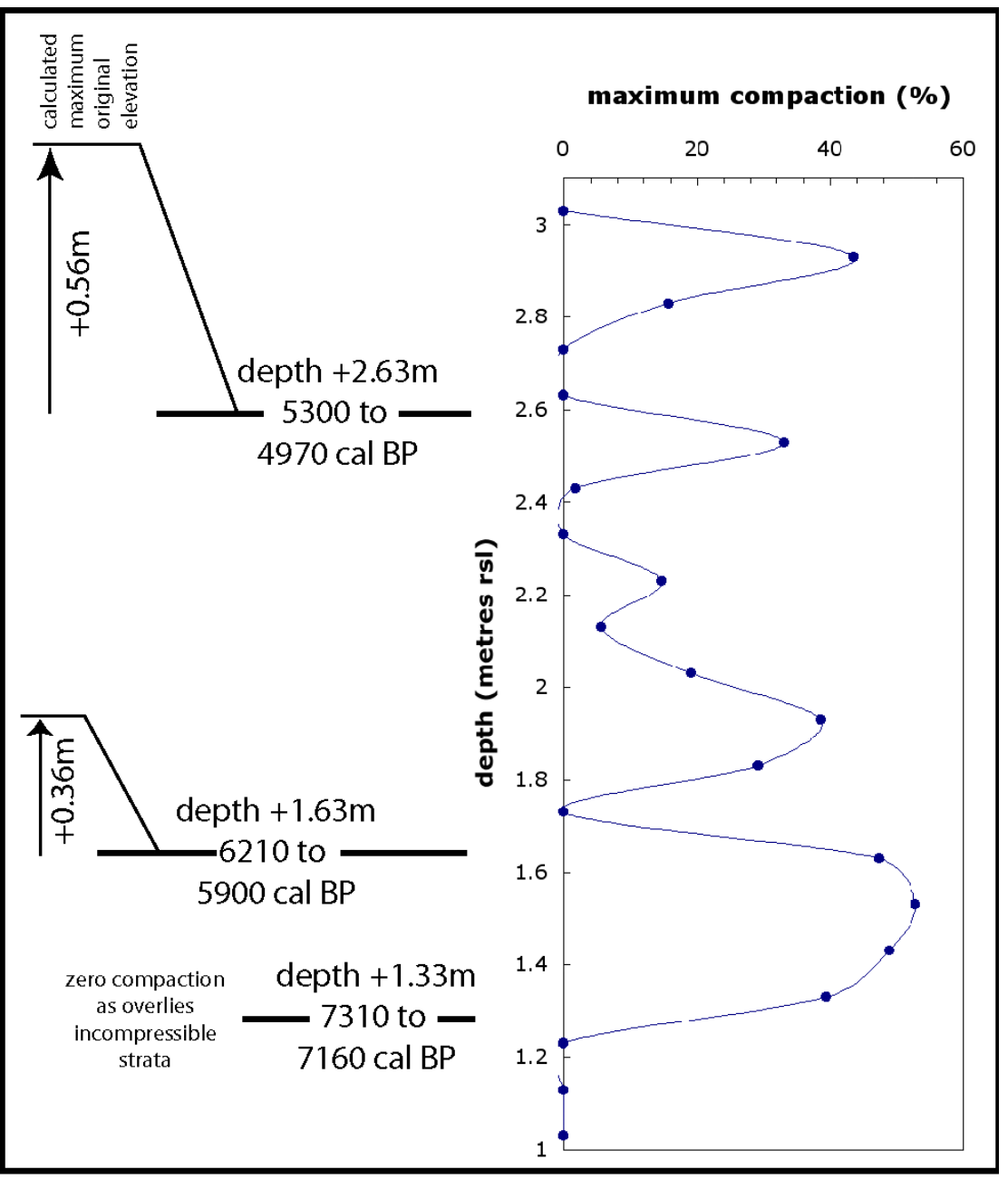

Figure 9 Percent compaction calculated for each 10-cm interval of KCD-6. Also shown is the effect of "decompacting" the sediments on the elevation of samples selected for ${ }^{14} \mathrm{C}$ dating. The lowermost sample is immediately above incompressible basement, and, hence, cannot be lowered by compaction (errors same as for Figure 8).

The elevation of the dated sample from the top of the mangrove mud unit in KCD-6 has been lowered by up to $56 \mathrm{~cm}$ through compaction of the underlying $1.3 \mathrm{~m}$ of sediment. Allowing for this compaction, the sequence of organic-rich mangrove muds accreted at rates of $0.99-1.19 \mathrm{~mm} / \mathrm{yr}$ between $\sim 5000$ and $\sim 6000 \mathrm{cal}$ BP. The sea level during this period peaked at a mid-Holocene highstand of $\sim+2$ to $+3 \mathrm{~m}$ and then began to decline slowly (Hesp et al. 1998), so the mangrove sediments were readily able to maintain their position by vertical accretion. During this period, the mangroves sequestered $0.91 \mathrm{t} / \mathrm{ha} / \mathrm{yr}$ of carbon.

The uppermost dated sample in core LCK-4 has been lowered by up to $43 \mathrm{~cm}$ through compaction of the underlying $2 \mathrm{~m}$ of sediment (Figure 10 ), but the ${ }^{14} \mathrm{C}$ dates present several problems in interpretation. It is clear that the mangrove sediments began accumulating $\sim 7850 \mathrm{cal} B P$, but the upper 2 dates in the sequence are reversed, and assuming either leads to very low sediment accretion rates 


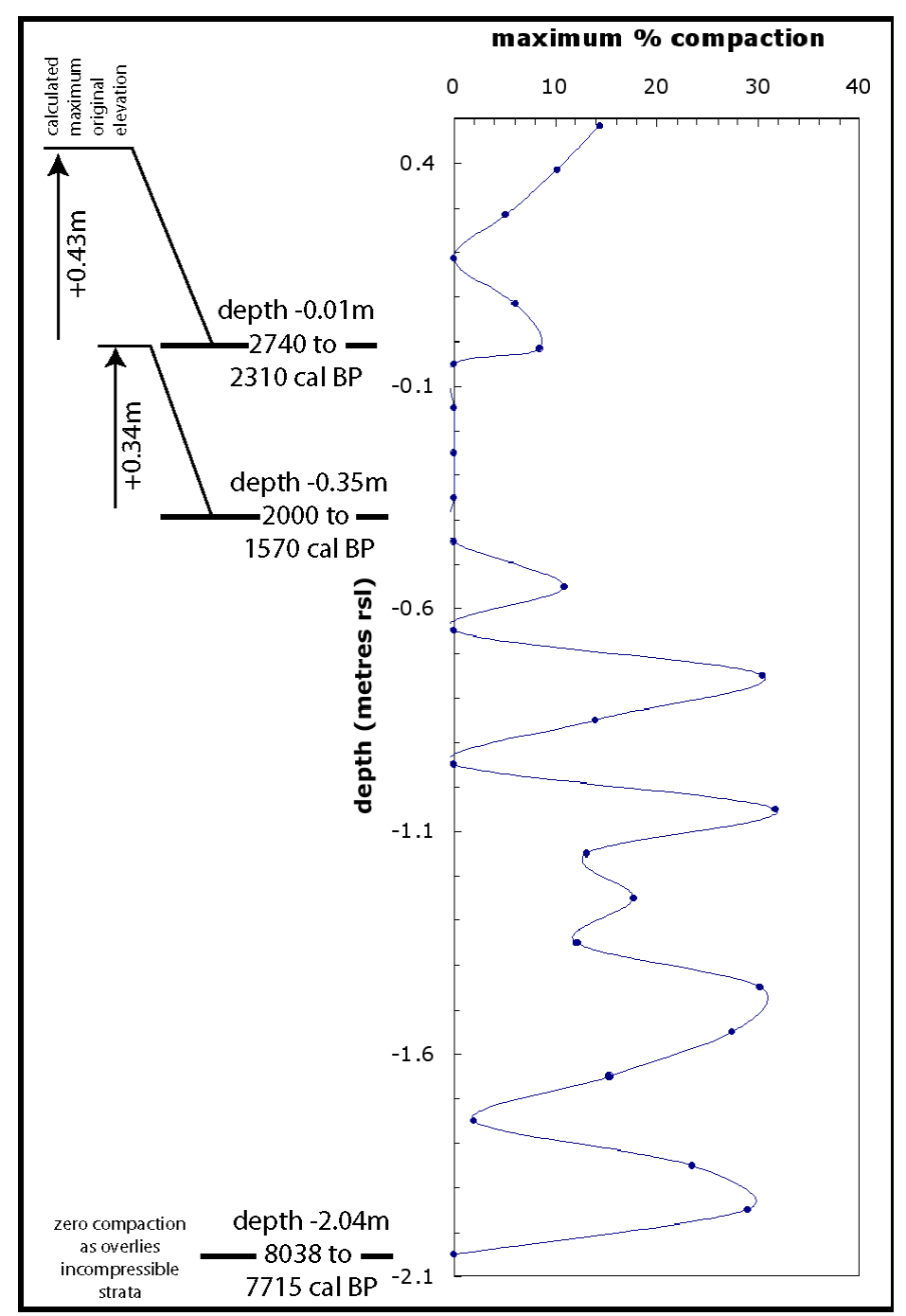

Figure 10 Percent compaction calculated for each 10-cm interval of LCK-4. Also shown is the effect of "decompacting" the sediments on the elevation of samples selected for ${ }^{14} \mathrm{C}$ dating. The lowermost sample is immediately above incompressible basement, and, hence, cannot be lowered by compaction (errors same as for Figure 8).

$(0.31-0.38 \mathrm{~mm} / \mathrm{yr})$ and very low carbon sequestration rates $(0.17 \mathrm{t} / \mathrm{ha} / \mathrm{yr})$ for such an organic-rich mangrove peat. Three km west of LCK-4 at Sungei Buloh, a similar mangrove peat accreted at a rate of $\sim 2.3 \mathrm{~mm} / \mathrm{yr}$ between 7250 and $7900 \mathrm{cal}$ BP (Chua 2002). The peat at Sungei Buloh is truncated at the modern low tide mark by marine erosion and forms part of a wide shore platform. The same low-tide platform composed of truncated early Holocene mangrove sediments occurs immediately in front of the LCK-4 location. Thus, it seems likely that the increase in coarse sandy material above $-0.45 \mathrm{~m}$ in the core marks an erosional surface, cut as the sea retreated from its mid-Holocene highstand (Hesp et al. 1998). A new series of mangrove sediments prograded over the erosional surface around 2000 cal BP. Therefore, no sediment accretion rates or carbon sequestration rates can be calculated for this core. It is clear from the bulk density data that the lower portions of the sequence 
have been compacted by up to $30 \%$, while sediments currently above mean sea level have been compacted very little $(<15 \%)$, consistent with burial depth being important in determining the degree of compaction.

Comparison between the mangrove sediments of MAR-5 and KCD-6 provides a consistent picture of accretion and carbon sequestration. The mangrove sediments in MAR-5 accumulated at a time when the sea level was rising rapidly and were subsequently buried under $9 \mathrm{~m}$ of sediment, while KCD-6 accumulated when sea-level change was slow and the sequence was not deeply buried. Hence, it is not surprising that the accretion rates, carbon sequestration rates, and degree of compaction calculated for the mangrove sediments of MAR- 5 are all considerably higher than for KCD-6 (Table 2).

The accretion rates calculated for mangrove units in MAR-5 and KCD-6 (total range $=0.99$ to $6.84 \mathrm{~mm} / \mathrm{yr}$ ) compare favorably with values calculated for other mangrove areas. Ellison (1998) has compiled a summary of short-term sediment accumulation rates in 9 modern mangrove sediments and found a total range from $0.6-10.0 \mathrm{~mm} / \mathrm{yr}$. In contrast, long-term sediment accretion rates based on carbon dating of Holocene mangrove sequences have yielded a smaller range of values between 0.7 and $1.8 \mathrm{~mm} / \mathrm{yr}$ (Woodroffe 1981; Ellison 1989; Ellison and Stoddart 1991; Ellison 1993), but none of these authors considered the effects of autocompaction in their studies, and, hence, the published Holocene rates may be biased towards lower values.

Likewise, the carbon sequestration rates calculated for the mangrove units of MAR-5 and KCD-6 ( 1.70 and $0.91 \mathrm{t} / \mathrm{ha} / \mathrm{yr}$, respectively) compare favorably with the rates calculated on centennial to millennial timescales for mangroves in the Asia-Pacific region which range between 0.14 and $2.98 \mathrm{t} / \mathrm{ha} / \mathrm{yr}$ (Fujimoto 2000).

\section{CONCLUSIONS}

This study has demonstrated that there are predictable empirical relationships between the dry bulk density of a modern surface sample and its organic matter content and particle size distribution. Thus, for a sample buried in a sedimentary sequence, the measured dry bulk density of the sample can be compared with an estimate of the initial bulk density derived from the physical characteristics of the sample (grain size distribution and organic carbon content) in order to obtain an estimate of the maximum amount of autocompaction experienced by the sample. Using this approach, it has been demonstrated that significant autocompaction can occur even when a sediment interval has been subjected to a load equivalent to $<2 \mathrm{~m}$ of overlying sediments. Inorganic sands appear less susceptible to autocompaction than organic-rich and/or fine-grained sediment.

The average maximum compactions for 3 mangrove sediment sequences ranged from $17-55 \%$, indicating that significant subsidence of samples selected for ${ }^{14} \mathrm{C}$ dating from within compressible intertidal sedimentary sequences can occur even when the thickness of compressible sediment beneath the sample is $<1 \mathrm{~m}$. The approach is likely to be most useful when the total thickness of the sediment pile is comparatively small (generally less than a few meters, depending on sediment characteristics), and in this study yielded rates of sediment accretion and carbon sequestration within the range observed for mangroves sediments elsewhere.

The advantage of the approach used in this study is that it is based on readily quantifiable physical characteristics of the sediment, but its drawback is that it provides only a maximum estimate of autocompaction. Combining this approach, however, with a time-dependent modeling approach, such as 
employed by Allen (2000), should yield better estimates of the magnitude of autocompaction than either approach used in isolation.

\section{ACKNOWLEDGEMENTS}

This work was supported by a grant RP19/01 from the Academic Research Fund of the National Institute of Education, Nanyang Technological University. The authors would like to acknowledge N Shirlaw, N Osbourne, and H Rosser of the Land Transport Authority of Singapore, and J Lai of the National Parks Board for facilitating access to the sites sampled for this study. L Vellen assisted with AMS target preparation.

\section{REFERENCES}

Allen JRL. 2000. Holocene coastal lowlands: autocompaction and the uncertain ground. In: Pye K, Allen JRL, editors. Coastal and estuarine environments: sedimentology, geomorphology and geoarchaeology. Geological Society Special Publication 175:239-52.

Alongi D, Tirendi F, Dixon P, Trott LA, Brunskill GJ. 1999. Mineralization of organic matter in intertidal sediments of a tropical semi-enclosed delta. Estuarine Coastal and Shelf Science 48:451-67.

Alongi D, Tirendi F, Clough BF. 2000. Below-ground decomposition of organic matter in forests of the mangroves, Rhizophora stylosa and Avicennia marina, along the arid coast of Western Australia. Aquatic Botany 68:97-122.

Alongi D, Wattayakorn G, Pfitzner J, Tirendi F, Zagorskis I, Brunskill GJ, Davidson A, Clough BF. 2001. Organic carbon accumulation and metabolic pathways in sediments of mangrove forests in southern Thailand. Marine Geology 179:85-103.

Blasco F, Saenger P, Janodet E. 1996. Mangroves as indicators of coastal change. Catena 27:167-78.

Chua CW. 2003. Environmental History of the Sungei Buloh-Kranji Mangrove coast. [BA honors thesis]. Singapore: Nanyang Technological University.

Ellison JC. 1989. Pollen analysis of mangrove sediments as a sea-level indicator. Palaeogeography, Palaeoclimatology and Palaeoecology 74:327-41

Ellison JC. 1993. Mangrove retreat with rising sea-level,
Bermuda. Estuarine, Coastal and Shelf Science 37: 75-87.

Ellison JC. 1998. Impacts of sediment burial on mangroves. Marine Pollution Bulletin 37:420-6.

Ellison JC, Stoddart DR. 1991. Mangrove ecosystem collapse with predicted sea-level rise: Holocene analogues and implications. Journal of Coastal Research 7:151-65.

Fujimoto K. 2000. Below-ground carbon sequestration of mangrove forests in the Asia-Pacific region. International Workshop Asia-Pacific Cooperation on Research for Conservation of Mangroves. 26-30 March 2000, Okinawa, Japan.

Hesp PA, Chang CH, Hilton M, Ming CL, Turner IM. 1998. A first tentative Holocene sea-level curve for Singapore. Journal of Coastal Research 14:308-14.

Pirazzoli PA. 1996. Sea-Level Changes. The Last 20,000 Years. Chichester: John Wiley.

Stanley DJ, Hait AK. 2000. Deltas, radiocarbon dating, and measurements of sediment storage and subsidence. Geology 28:295-8.

Stuiver M, Reimer PJ, Braziunas TF. 1998. High-precision radiocarbon age calibration for terrestrial and marine samples. Radiocarbon 40(3):1127-51. (Data available at http://www.calib.org/).

Woodroffe CD. 1981. Mangrove swamp stratigraphy and Holocene transgression, Grand Cayman Island, West Indies. Marine Geology 41:271-94. 